\title{
Novel PET Probes Specific for Deoxycytidine Kinase
}

Chengyi J. Shu*1, Dean O. Campbell*2,3, Jason T. Lee ${ }^{2,3}$, Andrew Q. Tran ${ }^{2,3}$, Jordan C. Wengrod ${ }^{2-4}$, Owen N. Witte ${ }^{2,3,5,6}$, Michael E. Phelps ${ }^{2,3}$, Nagichettiar Satyamurthy ${ }^{2,3}$, Johannes Czernin ${ }^{2,3}$, and Caius G. Radu ${ }^{2,3}$

${ }^{1}$ Division of Immunology, The Netherlands Cancer Institute, Amsterdam, The Netherlands; ${ }^{2}$ Department of Molecular and Medical Pharmacology, UCLA, Los Angeles, California; ${ }^{3}$ Crump Institute for Molecular Imaging, UCLA, Los Angeles, California;

${ }^{4}$ New York University School of Medicine, New York, New York; ${ }^{5}$ Howard Hughes Medical Institute, UCLA, Los Angeles, California; and ${ }^{6}$ Department of Microbiology, Immunology, and Molecular Genetics, David Geffen School of Medicine, UCLA,

Los Angeles, California

Deoxycytidine kinase $(\mathrm{dCK})$ is a rate-limiting enzyme in the deoxyribonucleoside salvage pathway and a critical determinant of therapeutic activity for several nucleoside analog prodrugs. We have previously reported the development of 1-(2'-deoxy2 '-18F-fluoro- $\beta$-D-arabinofuranosyl)cytosine (18F-FAC), a new probe for PET of dCK activity in immune disorders and certain cancers. The objective of the current study was to develop PET probes with improved metabolic stability and specificity for dCK. Toward this goal, several candidate PET probes were synthesized and evaluated in vitro and in vivo. Methods: High-pressure liquid chromatography was used to analyze the metabolic stability of ${ }^{18} \mathrm{~F}-\mathrm{FAC}$ and several newly synthesized analogs with the natural D-enantiomeric sugar configuration or the corresponding unnatural L-configuration. In vitro kinase and uptake assays were used to determine the affinity of the ${ }^{18} \mathrm{~F}-\mathrm{FAC}$ L-nucleoside analogs for dCK. The biodistribution of selected L-analogs in mice was determined by small-animal PET/CT. Results: Candidate PET probes were selected using the following criteria: low susceptibility to deamination, high affinity for purified recombinant dCK, high uptake in dCK-expressing cell lines, and biodistribution in mice reflective of the tissue-expression pattern of dCK. Among the 10 newly developed candidate probes, $\quad 1-\left(2^{\prime}\right.$-deoxy-2' -18 F-fluoro- $\beta$-L-arabinofuranosyl)cytosine (L-18F-FAC) and 1-(2'-deoxy-2'-18 F-fluoro- $\beta$-L-arabinofuranosyl)-5-methylcytosine (L-18F-FMAC) most closely matched the selection criteria. The selection of $\mathrm{L}^{18} \mathrm{~F}-\mathrm{FAC}$ and $\mathrm{L}-{ }^{18} \mathrm{~F}-$ FMAC was validated by showing that these two PET probes could be used to image animal models of leukemia and autoimmunity. Conclusion: Promising in vitro and in vivo data warrant biodistribution and dosimetry studies of L-18F-FAC and $\mathrm{L}^{18} \mathrm{~F}-$ FMAC in humans.

Key Words: deoxycytidine kinase (dCK); cytidine deaminase (CDA); PET probes; deoxyribonucleoside salvage; autoimmune; malignant lymphoproliferation

J Nucl Med 2010; 51:1092-1098

DOI: 10.2967/jnumed.109.073361

Received Nov. 30, 2009; revision accepted Mar. 12, 2010.

For correspondence or reprints contact: Caius G. Radu, Department of Molecular and Medical Pharmacology, UCLA, 700 Westwood Plaza, Box 951770, Los Angeles, CA 90024.

E-mail: CRadu@mednet.ucla.edu

${ }^{*}$ Contributed equally to this work.

Guest Editor: Leonard Wiebe, University of Alberta

COPYRIGHT $\odot 2010$ by the Society of Nuclear Medicine, Inc. eoxycytidine kinase (dCK) catalyzes a rate-limiting phosphorylation step in the deoxyribonucleoside salvage pathway (1). dCK is unique among salvage enzymes because of its ability to provide cells with all four deoxyribonucleoside triphosphates via direct (deoxycytidine triphosphate, deoxyadenosine triphosphate, and deoxyguanosine triphosphate) and indirect (thymidine triphosphate) mechanisms (Supplemental Fig. 1; supplemental materials are available online only at http://jnm.snmjournals.org) (1). The highest levels of dCK are found in lymphocytes (2,3), particularly during lymphopoiesis (1). dCK expression is upregulated in activated T cells (4). dCK is also expressed in most lymphoid and myeloid malignancies and in some solid tumors (1).

We have recently demonstrated a critical requirement for $\mathrm{dCK}$ in normal lymphocyte development in vivo (5). This requirement suggests that the rate-limiting function of $\mathrm{dCK}$ in deoxyribonucleoside phosphorylation is biologically significant. Moreover, dCK is therapeutically important. dCK phosphorylates and activates cytarabine, fludarabine, gemcitabine, cladribine, decitabine, and clofarabine (6). These nucleoside analogs are mainstay cytotoxic prodrugs in the treatment of hematologic and solid tumors. Cladribine has completed phase III clinical trials in multiple sclerosis (7). Lamivudine and emtricitabine, two other dCK-dependent nucleoside analogs, are approved by the Food and Drug Administration for treatment of HIV infections (8).

A common thread among dCK-dependent prodrugs is the high degree of variability in their therapeutic responses. This heterogeneity may reflect genetic variations in deoxyribonucleoside metabolism (9), which confer resistance to therapy. Because decreased dCK activity is a common drug-resistance mechanism (10), dCK-specific PET probes may enable patient stratification into likely responders and nonresponders to dCK-activated prodrugs.

We have recently described the development of 1-( $2^{\prime}-$ deoxy- $2{ }^{\prime}-{ }^{18}$ F-fluoro- $\beta$-D-arabinofuranosyl)cytosine $\left({ }^{18} \mathrm{~F}\right.$-FAC) 
(Fig. 1A) $(4,11)$, a new probe for PET of the deoxyribonucleoside salvage pathway. In mice, ${ }^{18} \mathrm{~F}-\mathrm{FAC}$ small-animal PET enables imaging of adaptive immunity and several types of cancer (4). ${ }^{18} \mathrm{~F}-\mathrm{FAC}$ accumulation in tumor tissues is predictive of responses to gemcitabine (12). Here, we analyzed the metabolic stability of ${ }^{18} \mathrm{~F}-\mathrm{FAC}$. In mice, ${ }^{18} \mathrm{~F}-\mathrm{FAC}$ was found to rapidly undergo deamination to $1-\left(2^{\prime}-\right.$ deoxy- $2^{\prime}-{ }^{18} \mathrm{~F}-$ fluoro- $\beta$-D-arabinofuranosyl) uracil ( $\left.{ }^{18} \mathrm{~F}-\mathrm{FAU}\right)$. Deamination confounds the specificity of ${ }^{18} \mathrm{~F}-\mathrm{FAC}$ for $\mathrm{dCK}$, and it may decrease its sensitivity in species with high deaminase activity such as humans (13). To bypass tracer deamination, a series of ${ }^{18} \mathrm{~F}-\mathrm{FAC}$ analogs was synthesized and evaluated. These studies indicated that ${ }^{18} \mathrm{~F}$-FAC analogs with the unnatural L-enantiomeric sugar configuration resist deamination and allow PET imaging of dCK activity in vivo.

\section{MATERIALS AND METHODS}

Radiochemical Synthesis of ${ }^{18} \mathrm{~F}$-Labeled PET Probes

${ }^{18} \mathrm{~F}-\mathrm{FAC}$ was synthesized as previously described $(4,11)$. The radiochemical syntheses of the new probes are described in the "Supporting Methods" section of the supplemental material.

\section{PET Probe Metabolite Analyses}

Mice were injected intravenously with ${ }^{18} \mathrm{~F}$-labeled probes and allowed up to $45 \mathrm{~min}$ of uptake. Tissues were removed and homogenized. Whole-blood sampling was performed via retroorbital eye bleeding, followed by centrifugation to obtain plasma. Tissues and plasma were treated with a mixture of methanol:acetonitrile (1:9) to extract nucleosides. After centrifugation, supernatants were evaporated at $50^{\circ} \mathrm{C}$ under nitrogen. The residue was dissolved in $100 \mathrm{~mL}$ of mobile phase (5 mM pentane-1-sulfonic acid, $\mathrm{pH} 3.1$, and methanol [96:4]), filtered, and injected into a $\mu$ Bondapak C18 column (Waters) with a flow rate of $1.5 \mathrm{~mL} / \mathrm{min}$. Peak radioactivity was measured using a Bioscan coincidence detector.

\section{In Vitro Enzymatic Assays}

The production of recombinant human cytidine deaminase (CDA) and dCK is described in the "Supporting Methods" section of the supplemental material. The deamination assay solution contained purified CDA $(0.05 \mu \mathrm{g} / \mu \mathrm{L})$ and $140 \mu \mathrm{M}$ nucleoside analog in $0.125 \mathrm{M}$ phosphate buffer, $\mathrm{pH}$ 7.6. The assay was performed at $37^{\circ} \mathrm{C}$ for $1 \mathrm{~h}$; products were resolved via highperformance liquid chromatography (HPLC) using a $\mu$ Bondapak C18 column $(3.9 \times 300 \mathrm{~mm})$, as previously reported (14). Elution was isocratic, using 3\% methanol in $0.1 \mathrm{M}$ phosphate buffer ( $\mathrm{pH}$ 5.5) at a flow rate of $1 \mathrm{~mL} / \mathrm{min}$. The rate of dCK-catalyzed phosphorylation was measured continuously at $340 \mathrm{~nm}$ using an iEMS Reader MF (LabSystems) system and a modification of a previously described spectrophotometric assay consisting of a coupled lactate dehydrogenase (LDH)-pyruvate kinase (PK) reaction (15). Reactions were performed in triplicate at $37^{\circ} \mathrm{C}$ with $50 \mathrm{mM}$ Tris- $\mathrm{HCl}$, $\mathrm{pH} 7.6 ; 50 \mathrm{mM} \mathrm{KCl} ; 10 \mathrm{mM} \mathrm{MgCl} 2 ; 5 \mathrm{mM}$ adenosine triphosphate; $0.2 \mathrm{mM}$ NADH; $1 \mathrm{mM}$ phosphoenolpyruvate; $1 \mathrm{mM}$ DTT; $1.4 \mu \mathrm{M}$ dCK; and 10 units of PK (Sigma) and 15 units of LDH per milliliter (Sigma). Kinetic constants were calculated using GraphPad Prism 5 (GraphPad Software).
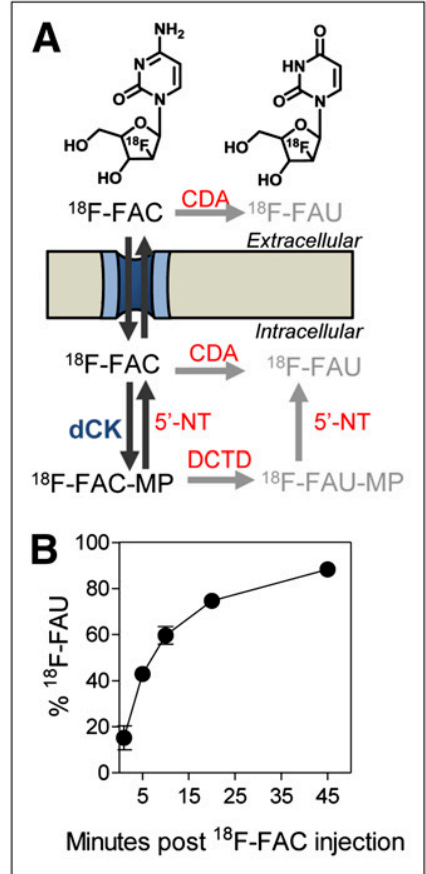

FIGURE 1. In vivo metabolite analysis of ${ }^{18} \mathrm{~F}-\mathrm{FAC}$. (A) Chemical structures of ${ }^{18} \mathrm{~F}-\mathrm{FAC}$ and ${ }^{18} \mathrm{~F}-\mathrm{FAU}$ and schematic showing extracellular and intracellular routes by which ${ }^{18} \mathrm{~F}-\mathrm{FAC}$ can be deaminated to ${ }^{18} \mathrm{~F}-$ FAU. (B) Percentage of total detected radioactivity in plasma that is attributable to ${ }^{18} \mathrm{~F}-\mathrm{FAC}$ over time as determined by HLPC analysis. Analysis is performed after intravenous injection of ${ }^{18} \mathrm{~F}-\mathrm{FAC}$ in mice. $5^{\prime}-\mathrm{NT}=5^{\prime}$ nucleotidase; DCTD = deoxycytidylate deaminase (catabolic enzymes are shown in red fonts); $M P=$ monophosphate.

\section{Cell-Based Phosphorylation and Uptake Competition Assays Using ${ }^{3} \mathrm{H}$-Labeled Deoxycytidine $\left({ }^{3} \mathrm{H}-\mathrm{dC}\right)$}

L1210 cells (12) were lysed by three cycles of freeze-thawing in $50 \mathrm{mM}$ Tris- $\mathrm{HCl}, \mathrm{pH}$ 7.6; 2 mM DTT; $20 \%$ glycerol; and $0.5 \%$ Nonident P40 (Roche). The lysate was clarified by centrifugation $(15,000 \mathrm{~g}$ for $10 \mathrm{~min})$, and the protein concentration in the supernatants was determined using the Bradford assay. The kinase reaction mixture contained $4.2 \mu \mathrm{g}$ of L1210 lysate; $3 \mu \mathrm{M}{ }^{3} \mathrm{H}-\mathrm{dC}$ (Moravek Biochemicals; specific activity, $1.295 \mathrm{TBq}[35 \mathrm{Ci}] /$ mmol); $50 \mathrm{mM}$ Tris- $\mathrm{HCl}$, pH 7.6; $5 \mathrm{mM} \mathrm{MgCl}$; $1 \mathrm{mM}$ UTP (Sigma); $2 \mathrm{mM}$ DTT; $10 \mathrm{mM} \mathrm{NaF}$; $1 \mathrm{mM}$ thymidine (to inhibit thymidine kinase 2); and $30 \mu \mathrm{M}$ nucleoside analog. The reaction was incubated at $37^{\circ} \mathrm{C}$ for $20 \mathrm{~min}$ and was stopped by the addition of $30 \mu \mathrm{L}$ of ice-cold water, followed by heating at $90^{\circ} \mathrm{C}$ for $3 \mathrm{~min}$. The reaction was then spotted on Whatman DE81 filter disks; these were washed 3 times with $4 \mathrm{mM}$ ammonium formate and 2 times with ethanol. The disks were placed in scintillation vials and counted using a Beckman Liquid Scintillation counter. For uptake assays, $38.85 \mathrm{kBq}(1.05 \mu \mathrm{Ci})$ of ${ }^{3} \mathrm{H}-\mathrm{dC}$ were added to $\mathrm{L} 1210$ cells ( $10^{5}$ cells per well in 96-well plates), followed by $3 \mu \mathrm{L}$ of $100 \mu \mathrm{M}$ stocks of each nucleoside analog (at a final volume of $100 \mu \mathrm{L} /$ well). After $1 \mathrm{~h}$ at $37^{\circ} \mathrm{C}$, wells were washed 3 times with ice-cold phosphate-buffered saline using a vacuum filtration system (Millipore). Plates were oven-dried at $45^{\circ} \mathrm{C}-50^{\circ} \mathrm{C}$ for $10 \mathrm{~min}$, and 200 $\mu \mathrm{L}$ of scintillation fluid were added per well. Radioactivity was measured using a Trilux MicroBeta scintillation counter (Perkin Elmer).

\section{Small-Animal PET/CT Studies in Mice}

In vivo studies followed the guidelines of the Department of Laboratory Animal Medicine at UCLA and were performed as previously described $(4,12)$ (Supplemental "Supporting Methods" section). Autoimmune B6.MRL-Fas ${ }^{l p r} / \mathrm{J}$ mice were obtained from the Jackson Laboratory (stock no. 000482). 


\section{Statistical Analysis}

Data are presented as mean \pm SD. All $P$ values are 2-tailed, and $P$ values of less than 0.05 were considered to be statistically significant. Graphs were generated using GraphPad Prism 5 software.

\section{RESULTS}

\section{${ }^{18}$ F-FAC Is Rapidly Deaminated In Vivo}

With the exception of the fluorine substitution of the ara$2^{\prime}$ hydrogen, FAC is identical to deoxycytidine. Therefore, it is likely that ${ }^{18} \mathrm{~F}$-FAC and deoxycytidine are competitive substrates and share the same metabolic pathway. According to the model shown in Figure $1 \mathrm{~A},{ }^{18} \mathrm{~F}-\mathrm{FAC}$ is either phosphorylated by cytosolic dCK to ${ }^{18} \mathrm{~F}$-FAC-monophosphate or converted to ${ }^{18} \mathrm{~F}-\mathrm{FAU}$ by extracellular or cytosolic CDA. ${ }^{18} \mathrm{~F}-\mathrm{FAU}$, a weak substrate for thymidine kinase 1 (TK1) (16), cannot be phosphorylated by dCK. ${ }^{18} \mathrm{~F}-\mathrm{FAU}$ can also be produced from ${ }^{18} \mathrm{~F}-\mathrm{FAC}$ by a CDA-independent mechanism involving deoxycytidylate deaminase (which converts ${ }^{18} \mathrm{~F}$-FAC-monophosphate to ${ }^{18} \mathrm{~F}$-FAU-monophosphate) and 5'nucleotidase (which dephosphorylates ${ }^{18} \mathrm{~F}$ FAU-monophosphate, producing ${ }^{18}$ F-FAU; Fig. 1A). To validate this model, mice were intravenously injected with ${ }^{18} \mathrm{~F}-\mathrm{FAC}$ and plasma samples were analyzed by HPLC. ${ }^{18} \mathrm{~F}-$ FAU was the only ${ }^{18}$ F-FAC metabolite detected in plasma by this HPLC method (Supplemental Fig. 2A). As early as 1 min after injection, ${ }^{18}$ F-FAU contributed to approximately $14 \%$ of the total radioactivity in the plasma (Fig. 1B). Ten minutes later, the contribution of ${ }^{18} \mathrm{~F}$-FAU increased to approximately $60 \%$ and reached approximately $90 \%$ at 45 min. The plasma clearance rate of ${ }^{18} \mathrm{~F}-\mathrm{FAU}$ was significantly slower than that of ${ }^{18}$ F-FAC (Supplemental Fig. 2B). Similar to plasma, thymus and liver samples from ${ }^{18} \mathrm{~F}$ FAC-injected mice also contained high concentrations of ${ }^{18}$ F-FAU (Supplemental Fig. 2C) at 45 min after injection.

2-Chloro-2' -Deoxy-2' -18F-Fluoro-9- $\beta$-D-Arabinofuranosyl-Adenine ( ${ }^{18} \mathrm{~F}-$ Clofarabine), a Potential dCK-Specific PET Probe That Resists Deamination

The fast exponential decline of ${ }^{18} \mathrm{~F}-\mathrm{FAC}$ in plasma and the accumulation of the ${ }^{18} \mathrm{~F}$-FAU metabolite in plasma and tissues reduce the specificity of ${ }^{18}$ F-FAC. They may also affect the sensitivity of ${ }^{18} \mathrm{~F}$-FAC PET in humans, who express twice as much deaminase activity as do mice in most tissues (13). This problem can be solved by identifying dCK substrates that are amenable to ${ }^{18} \mathrm{~F}$ labeling and have low affinity for deaminase enzymes. Clofarabine (Supplemental Fig. 3) is a dCK-dependent prodrug with excellent metabolic stability (17). The 2-halogenated aglycone of clofarabine confers resistance to deamination by adenosine deaminase. The $2^{\prime}$ fluorine atom blocks cleavage of the glycosidic bond by bacterial purine nucleoside phosphorylase (17). Clofarabine is efficiently phosphorylated by $\mathrm{dCK}$ (18) and is amenable to ${ }^{18} \mathrm{~F}$ labeling (Supplemental Fig. 3). Surprisingly, ${ }^{18}$ F-FAC and ${ }^{18} \mathrm{~F}-$ labeled clofarabine showed distinct biodistribution patterns in immunocompetent (C57BL/6J) mice (Fig. 2). In contrast to ${ }^{18} \mathrm{~F}$-FAC (4), ${ }^{18} \mathrm{~F}$-clofarabine accumulation in expected target organs such as the thymus, bone marrow, and spleen was undetectable. Whether the differences in the biodistribution of ${ }^{18} \mathrm{~F}$-FAC and ${ }^{18} \mathrm{~F}$-clofarabine are unique to mice or can also be found in other species, including humans, will be addressed in future studies.

\section{FAC Analogs as Potential dCK-Specific Probes}

The disappointing performance of ${ }^{18} \mathrm{~F}$-clofarabine in mice indicated that a different approach was required to solve the tracer deamination problem. Toward this end, the FAC pharmacophore was explored to seek pyrimidine analogs matching three criteria: amenability to routine ${ }^{18} \mathrm{~F}$ radiolabeling with high specific activity, resistance to deamination, and affinity for dCK comparable to that of ${ }^{18} \mathrm{~F}$ FAC. Nine potential dCK-specific probes (Fig. 3) were designed and synthesized. The rationale for selecting these compounds was two-fold. First, modifications of deoxycytidine at position 5 of the nucleobase have been shown to reduce susceptibility to deamination (19). Second, dCK has the unusual property of phosphorylating both D-enantiomers (the natural configuration of nucleosides) and unnatural L-enantiomers $(20,21)$. In contrast, CDA has a strong preference for D- over L-deoxycytidine analogs (20). The susceptibility of FAC analogs to deamination was determined by incubating them with purified recombinant human CDA, followed by HPLC analysis to determine the formation of deaminated products. Figure 3 shows that the nucleosides with the D-chirality were completely deaminated, whereas the unnatural L-nucleosides were resistant to deamination. Although these modifications solve the deamination problem, it is possible that they also reduce the affinity of the FAC analogs for dCK. This possibility was addressed using several assays.

First, an LDH and PK-coupled reaction (15) was used to determine the kinetic parameters of human recombinant $\mathrm{dCK}$ for L-analog candidate probes. Kinetic parameters for 3 of the 5 L-analogs were obtained (Table 1). L- ${ }^{18}$ F-FMAC and 1-(2'-deoxy-2'-fluoro- $\beta$-L-arabinofuranosyl)-5-chlorocytosine (L-FCAC) had similar kinetics, with $\mathrm{K}_{\mathrm{M}}$ values of 1.0 and $0.6 \mu \mathrm{M}$, respectively. These $\mathrm{K}_{\mathrm{M}}$ values were

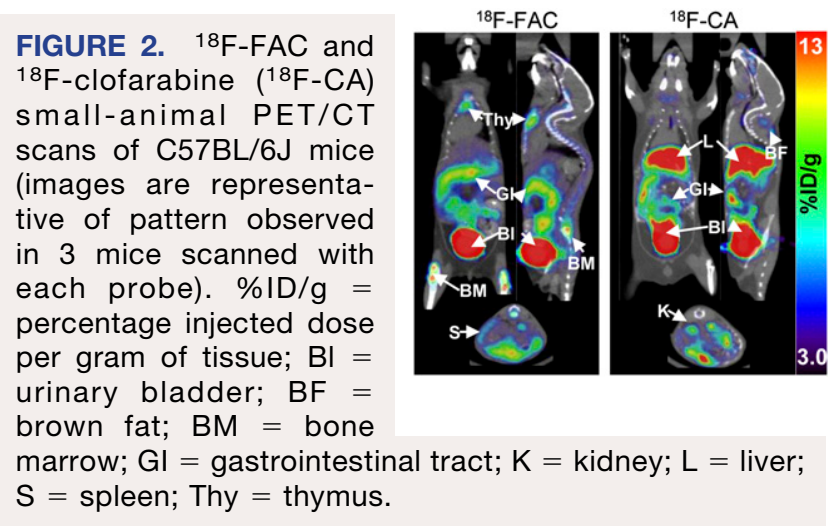




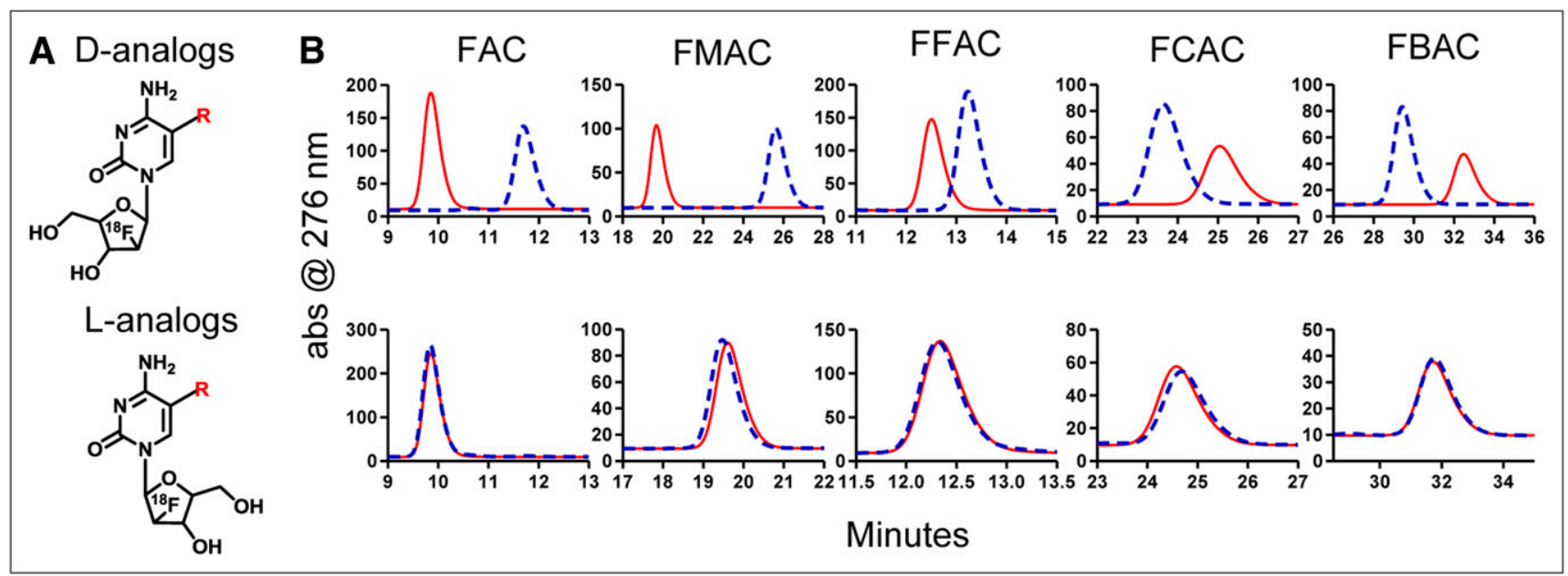

FIGURE 3. Candidate dCK-specific PET probes that resist deamination. (A) Chemical structures of deoxycytidine analogs amenable to ${ }^{18} \mathrm{~F}$ labeling. (B) In vitro deamination assay. After incubation at $37^{\circ} \mathrm{C}$ for $1 \mathrm{~h}$ in presence (blue dashed traces) or absence (red solid traces) of recombinant purified CDA, candidate probes were analyzed on HPLC. D-analogs are shown in top row, and L-analogs are shown in bottom row. abs = absorbance. $\mathrm{R}=\mathrm{H}(\mathrm{FAC}) ; \mathrm{R}=\mathrm{CH} 3(\mathrm{FMAC}) ; \mathrm{R}=\mathrm{F}(\mathrm{FFAC}) ; \mathrm{R}=\mathrm{Cl}(\mathrm{FCAC})$; $\mathrm{R}=\mathrm{Br}(\mathrm{FBAC})$

similar to those of FAC $(0.8 \mu \mathrm{M})$. L-FMAC and L-FCAC also had specificity constants $\left(\mathrm{k}_{\mathrm{cat}} / \mathrm{K}_{\mathrm{M}}\right)$ for $\mathrm{dCK}$ that were similar to those of FAC (0.96-1.2 times that of FAC). However, this was not the case for $1-\left(2^{\prime}\right.$-deoxy-2'-fluoro$\beta$-L-arabinofuranosyl)-5-bromo-cytosine (L-FBAC), which had a higher $\mathrm{K}_{\mathrm{M}}$ and a lower specificity constant than FAC.

The LDH-PK assay determines the kinetics only for phosphorylation reactions that are faster than the ultraviolet-induced decomposition of NADH (22). The inability to obtain the kinetic parameters for L-FAC and 1-(2'-deoxy-2'fluoro- $\beta$-L-arabinofuranosyl)-5-fluoro-cytosine (L-FBAC) using the LDH-PK assay indicated that these nucleoside analogs either are high-affinity substrates for dCK, with low enzymatic turnover, or that they lack affinity for dCK. To determine whether L-FAC and L-FFAC were phosphorylated by dCK, kinase assays (23) were performed using ${ }^{18} \mathrm{~F}$-labeled probes (synthesized according to the scheme shown in Supplemental Fig. 4), purified recombinant human dCK, and lysates from L1210 dCK-positive and -negative cell lines (12). The kinase assays showed conclusively that L-FAC and L-FFAC are indeed dCK substrates (Supplemental Fig. 5).

Two cell-based assays were then used to determine whether the L-analogs can compete with the endogenous dCK substrate deoxycytidine. In a kinase assay using whole-cell lysates of the dCK-positive murine leukemia cell line L1210 (12), L-FAC and L-FFAC outperformed the other nucleoside analogs by inhibiting ${ }^{3} \mathrm{H}-\mathrm{dC}$ phosphorylation by over $95 \%$ (Fig. 4). The enhanced activity of dCK toward L-FAC and L-FFAC, compared with FAC, is not entirely surprising because the enzyme has been previously shown to favor the L-conformation of other pyrimidine analogs $(21,24)$. Confirming the results from the LDH-PK assay, L-FBAC inhibited deoxycytidine phosphorylation by only $32 \%$. The ability of L-nucleosides to competitively inhibit ${ }^{3} \mathrm{H}-\mathrm{dC}$ uptake by $\mathrm{L} 1210$ cells was also determined (Fig. 4). In addition to dCK-mediated phosphorylation, the uptake assay took into account the efficiency of transport across the cell membrane. L-FAC and L-FFAC reduced the uptake of ${ }^{3} \mathrm{H}-\mathrm{dC}$ by at least $90 \%$. The inhibition by L-FCAC and L-FMAC was $32 \%-35 \%$.

\section{Biodistribution of ${ }^{18} \mathrm{~F}$-Labeled L-Nucleosides in Immunocompetent C57BL/6J Mice}

Results from the in vitro phosphorylation and uptake assays narrowed down the selection of candidate L-enantiomer probes to $\mathrm{L}^{-18} \mathrm{~F}-\mathrm{FAC}, \mathrm{L}^{-18}{ }^{18} \mathrm{~F}-\mathrm{FMAC}, \mathrm{L}^{-18} \mathrm{~F}-\mathrm{FFAC}$, and $\mathrm{L}^{18}{ }^{18} \mathrm{~F}-\mathrm{FCAC}$. Similar to ${ }^{18} \mathrm{~F}-\mathrm{FAC}$ and unlike ${ }^{18} \mathrm{~F}-$ clofarabine, all four candidate probes accumulated in the thymus and to varying degrees in the bone marrow and spleen (Fig. 5A). Figure 5B shows the relative probe uptake values in dCK-positive tissues normalized to uptake in the muscle (a dCK-negative tissue); absolute probe uptake values are shown in Supplemental Figure 6. Among the tested L-nucleosides, $\mathrm{L}^{-1}{ }^{18} \mathrm{~F}-\mathrm{FCAC}$ had the lowest uptake in lymphoid tissues and $\mathrm{L}^{-18} \mathrm{~F}-\mathrm{FAC}$ had the highest uptake in

\begin{tabular}{|c|c|c|c|}
\hline Probe & $\mathrm{K}_{\mathrm{M}}(\mu \mathrm{M})$ & Relative $\mathrm{k}_{\text {cat }}$ & Relative $\mathrm{K}_{\text {cat }} / \mathrm{K}_{\mathrm{M}}$ \\
\hline FAC & $0.76 \pm 0.15$ & 1.0 & 1.0 \\
\hline L-FMAC & $1.02 \pm 0.15$ & 1.0 & 0.96 \\
\hline L-FCAC & $0.61 \pm 0.09$ & 0.96 & 1.20 \\
\hline L-FBAC & $6.54 \pm 0.99$ & 2.70 & 0.31 \\
\hline $\begin{array}{l}\mathrm{k}_{\text {cat }} \text { and } \\
\text { purified rec } \\
\text { to FAC. }\end{array}$ & $\begin{array}{l}\text { ecificity cons } \\
\text { nbinant huma }\end{array}$ & $\begin{array}{l}\text { nt }\left(\mathrm{K}_{\mathrm{cat}} / \mathrm{K}_{\mathrm{M}}\right) \text { we } \\
\mathrm{dCK} \text {, and valu }\end{array}$ & $\begin{array}{l}\text { determined using } \\
\text { are given relative }\end{array}$ \\
\hline
\end{tabular}




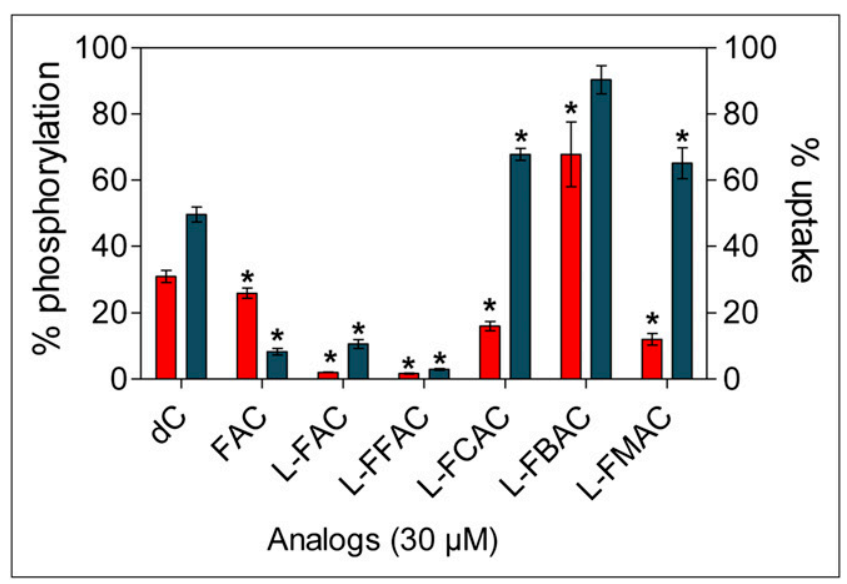

FIGURE 4. Analyses of affinity of L-analogs for dCK. L-analogs were tested for their ability to competitively inhibit phosphorylation (red bars; left axis) and uptake (blue bars; right axis) of tritium-labeled deoxycytidine $\left({ }^{3} \mathrm{H}-\mathrm{dC}\right)$ using dCK-expressing L1210 cells. Results represent 2 independent experiments. $P$ values are calculated relative to water $(n=3)$. ${ }^{\star} P<0.05 . \mathrm{dC}=$ deoxycytidine.

thymus and spleen. An intermediate profile was observed for $\mathrm{L}^{-18} \mathrm{~F}$-FMAC, which had higher uptake in the thymus and lower uptake in the spleen than did ${ }^{18} \mathrm{~F}$-FAC.
In addition to bone marrow and thymus retention, $\mathrm{L}^{18} \mathrm{~F}-$ FAC and $\mathrm{L}^{-18} \mathrm{~F}-\mathrm{FFAC}$ are also retained in the liver. Similar to ${ }^{18} \mathrm{~F}-3^{\prime}$-deoxy-3'-fluorothymidine $\left({ }^{18} \mathrm{~F}-\mathrm{FLT}\right) \quad(25)$, these probes accumulate in the liver by a nonspecific mechanism (26). Alternatively, the liver uptake may be dCK-specific. A novel dCK knockout mouse (5) can be used to evaluate these possibilities. L- ${ }^{18} \mathrm{~F}-\mathrm{FAC}$ small-animal PET/CT scans (Fig. 5C and Supplemental Fig. 7) indicate that, with the exception of excretory organs such as gallbladder and urinary bladder, the $\mathrm{L}^{-1}{ }^{18} \mathrm{~F}-\mathrm{FAC}$ organ distribution typically observed in wildtype mice (Fig. 5A) was absent in the dCK knockout mouse. Although these data demonstrate that the liver trapping of $\mathrm{L}^{18}{ }^{18} \mathrm{~F}-\mathrm{FAC}$ requires $\mathrm{dCK}$ expression, other mechanisms such as uptake via liver-specific transporters for unnatural L-nucleosides may also play a role.

\section{L-18F-FAC and L-18F-FMAC Small-Animal PET/CT of Malignant and Autoimmune Lymphoproliferative Disorders in Mice}

Biodistribution studies in healthy mice indicate that the deamination-resistant probes L- ${ }^{18} \mathrm{~F}-\mathrm{FAC}, \mathrm{L}-{ }^{18} \mathrm{~F}-\mathrm{FFAC}$, and $\mathrm{L}^{18}{ }^{18} \mathrm{~F}-\mathrm{FMAC}$ compare favorably with ${ }^{18} \mathrm{~F}-\mathrm{FAC}$. Although $\mathrm{L}^{-18} \mathrm{~F}-\mathrm{FMAC}$ had a slightly lower sensitivity than $\mathrm{L}^{-18} \mathrm{~F}-$ FAC and L- ${ }^{18} \mathrm{~F}-\mathrm{FFAC}$, its low liver uptake may be advantageous in certain applications. Because the biodistribution
FIGURE 5. Biodistribution of ${ }^{18} \mathrm{~F}-\mathrm{la}$ beled unnatural nucleosides in mice. (A) Small-animal PET/CT images of C57BL/ $6 \mathrm{~J}$ mice. (B) Quantification of PET data. Probe uptake was normalized to muscle background (absolute uptake values are shown in Supplemental Fig. 6). (C) L-18 F-FAC small-animal PET/CT scan of dCK knockout mouse. $P$ values were calculated relative to $F A C$ for each specific tissue. ${ }^{*} P<0.05 ; n=5\left({ }^{18} \mathrm{~F}\right.$ $\mathrm{FAC}), n=3$ (L-18 F-FAC), $n=3\left(\mathrm{~L}-{ }^{18} \mathrm{~F}-\right.$ FMAC), $n=2$ (L-18F-FFAC), and $n=2$ (L-18F-FCAC). \%ID/g = percentage injected dose per gram of tissue; $\mathrm{BI}=$ urinary bladder; B. Marrow = bone marrow; $\mathrm{BM}=$ bone marrow; $\mathrm{Gl}=$ gastrointestinal tract; $\mathrm{KO}=$ knockout; $\mathrm{L}=$ liver; $\mathrm{S}=$ spleen; $\mathrm{SG}=$ salivary gland; Thy $=$ thymus.
A L-18F-FAC

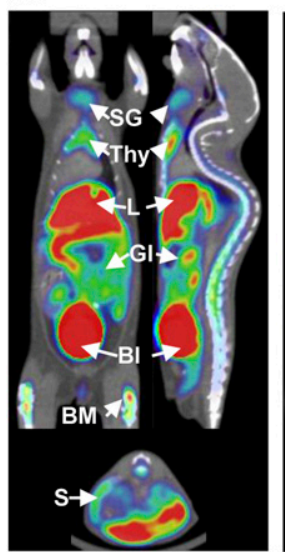

B
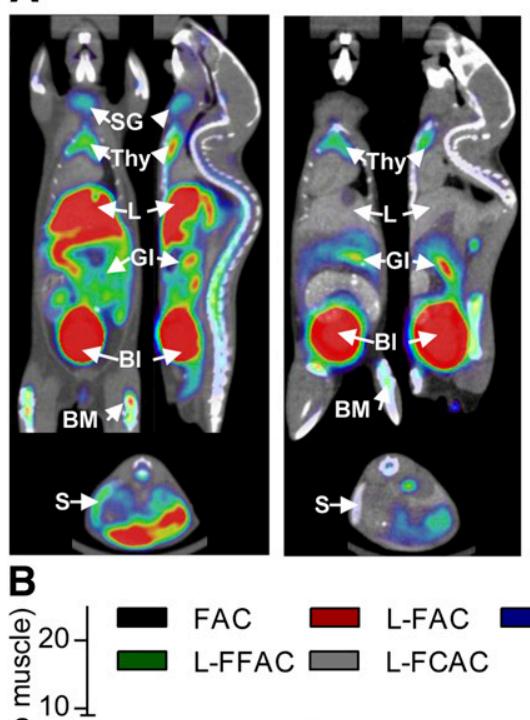

L-18F-FFAC

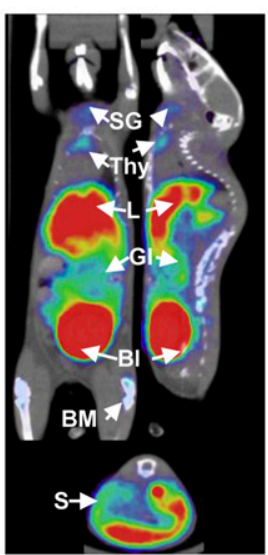

L-18F-FCAC
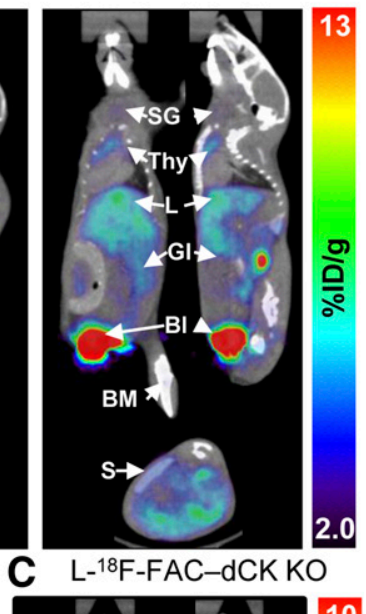

C $\quad$ L- ${ }^{18} \mathrm{~F}-\mathrm{FAC}-\mathrm{dCK}$ KO

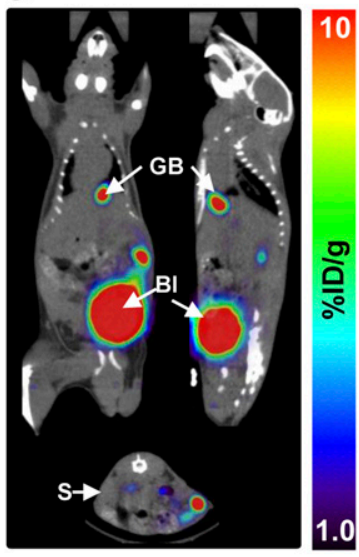


of $\mathrm{L}^{-18} \mathrm{~F}-\mathrm{FFAC}$ was similar to that of $\mathrm{L}^{-18} \mathrm{~F}-\mathrm{FAC}$, this probe was not selected for further evaluations. $\mathrm{L}^{-1}{ }^{18} \mathrm{~F}-\mathrm{FMAC}$ and $\mathrm{L}^{-18} \mathrm{~F}-\mathrm{FAC}$, the two remaining candidate probes, were compared in two mouse models of cancer and autoimmunity, previously used to evaluate ${ }^{18} \mathrm{~F}$-FAC $(4,12)$. The first test was to determine whether $\mathrm{L}^{-18}{ }^{18} \mathrm{~F}-\mathrm{FAC}$ and $\mathrm{L}^{18}{ }^{18} \mathrm{~F}-\mathrm{FMAC}$ could distinguish between isogenic murine L1210 leukemia cells that either express dCK (wild-type cells) or lack this enzyme (L1210-10K cells) (12). As shown in Figure 6A, dCK-positive tumors were detected with both $\mathrm{L}^{-18}{ }^{18} \mathrm{~F}-\mathrm{FAC}$ and $\mathrm{L}^{-18} \mathrm{~F}-\mathrm{FMAC}$. Neither of these probes accumulated in the dCK-negative L1210-10K tumors. L- $^{18} \mathrm{~F}-\mathrm{FAC}$ and $\mathrm{L}^{-18} \mathrm{~F}-\mathrm{FMAC}$ were then evaluated in the B6.MRL-Fas ${ }^{l p r} / J$ autoimmune mice $(27,28)$. Figure $6 \mathrm{~B}$ shows that both probes detected the cervical, axillary, and brachial lymphadenopathies characteristic of the Fas ${ }^{l p r}$ model.

\section{DISCUSSION}

Factors That May Affect Performance of ${ }^{18} \mathrm{~F}-\mathrm{FAC}$, L- ${ }^{18} \mathrm{~F}-\mathrm{FAC}$, and L- ${ }^{18} \mathrm{~F}-\mathrm{FMAC}$ in Preclinical and Clinical Applications

Despite its rapid deamination in vivo (Fig. 1B), ${ }^{18} \mathrm{~F}-\mathrm{FAC}$ performs well in mice $(4,12)$. A potential limitation of ${ }^{18} \mathrm{~F}-$ FAC concerns its muscle background, which is the highest among tested compounds (Supplemental Fig. 6). In applications in which muscle background may interfere with specific signals, ${ }^{18} \mathrm{~F}-\mathrm{FAC}$ could be replaced by $\mathrm{L}^{-18} \mathrm{~F}-$ FMAC, a probe with a similar biodistribution pattern and sensitivity but with a lower nonspecific uptake in the muscle. Regarding $\mathrm{L}^{-18} \mathrm{~F}-\mathrm{FAC}$, its utility in mice may be limited by the high liver uptake. Furthermore, it is conceivable that, because of their unnatural L-chirality, $\mathrm{L}^{-1}{ }^{18} \mathrm{~F}-\mathrm{FAC}$ and $\mathrm{L}^{-18} \mathrm{~F}-\mathrm{FMAC}$ may be transported less efficiently than ${ }^{18} \mathrm{~F}-\mathrm{FAC}$ across the plasma membrane.

In the context of clinical applications, the deaminationresistant probes $\mathrm{L}^{-18} \mathrm{~F}-\mathrm{FAC}$ and $\mathrm{L}^{-1}{ }^{18} \mathrm{~F}-\mathrm{FMAC}$ may have an advantage over ${ }^{18} \mathrm{~F}$-FAC given the high deamination activity in certain human tissues (13). Concerning the utility of the FAC probes for treatment stratification, ${ }^{18}$ F-FAC could be the best probe to use for predicting responses to deaminationsusceptible prodrugs such as cytarabine, gemcitabine, and decitabine. In contrast, $\mathrm{L}^{-18}{ }^{18} \mathrm{~F}-\mathrm{FAC}$ and $\mathrm{L}^{-18}{ }^{18} \mathrm{~F}-\mathrm{FMAC}$ may be more suitable for predicting responses to deaminationresistant drugs such as cladribine and clofarabine.

\section{Comparison Between TK1 and dCK-Specific PET Probes}

PET imaging of TK1 and dCK-the two rate-limiting enzymes in the deoxyribonucleoside salvage pathway-is now possible given the development of ${ }^{18} \mathrm{~F}$-FLT by Shields et al. in 1998 (26), followed by the identification of ${ }^{18} \mathrm{~F}$-FAC in 2008 (4) and optimized ${ }^{18}$ F-FAC analogs described herein. Direct comparisons between ${ }^{18} \mathrm{~F}-\mathrm{FLT}$ and the ${ }^{18} \mathrm{~F}-\mathrm{FAC}$ series of probes should take into account the fact that high levels of endogenous thymidine in rodent serum compete with ${ }^{18} \mathrm{~F}-$ FLT and reduce its sensitivity in mice (29). Nonetheless, it is likely that PET measurements of TK1 and dCK provide
A L-18F-FAC
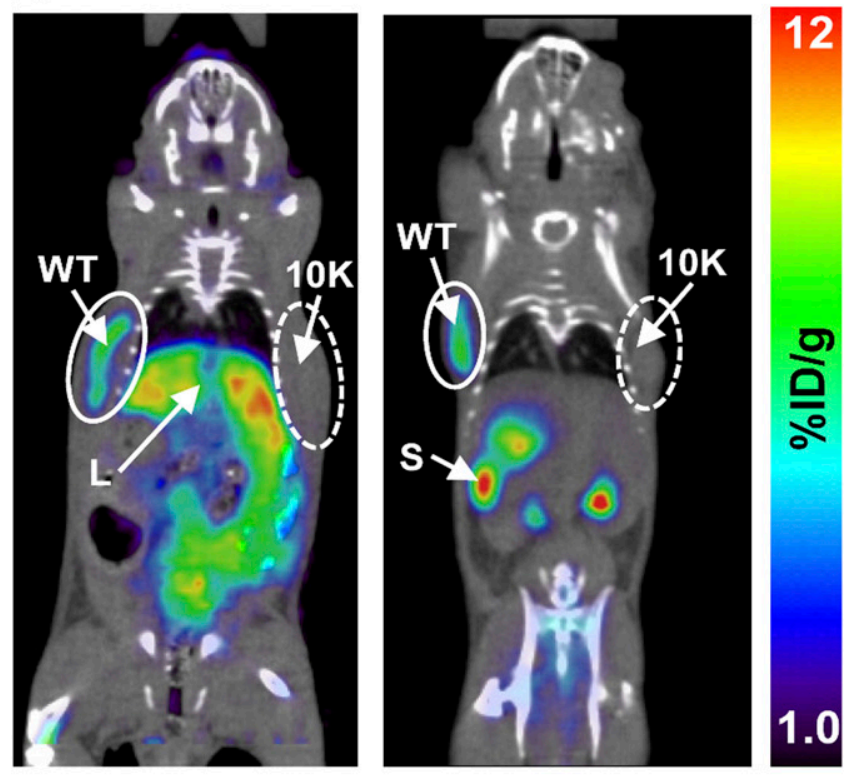

B L-18 F-FAC
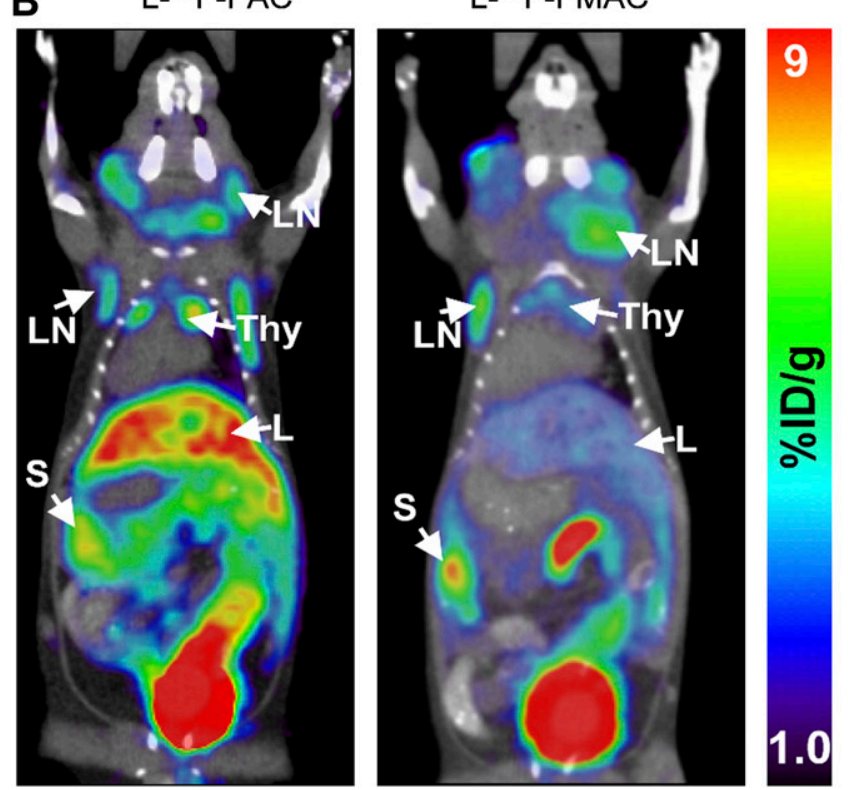

FIGURE 6. L-18F-FAC and L-18 F-FMAC small-animal PET/ CT images of malignant and autoimmune lymphoproliferative disorders. (A) L-18F-FAC and L-18F-FMAC small-animal PET/CT of L1210 lymphoma tumors. L1210 parental cell line (WT, solid-lined circle) and dCK-deficient variant L1210-10K (10K, dash-lined circle) were injected subcutaneously under the left and right shoulders of the mouse, respectively. Only the parental cell line accumulated both probes. (B) L-18 FFAC and L- ${ }^{18} \mathrm{~F}-\mathrm{FMAC}$ small-animal PET/CT of autoimmune B6.MRL-Fas ${ }^{/ p r / J}$ mice. Both probes detected cervical, axillary, and brachial lymphadenopathy in these mice. $\% \mathrm{ID} / \mathrm{g}=$ percentage injected dose per gram of tissue; $\mathrm{L}=$ liver; LN = lymph nodes; $\mathrm{S}=$ spleen; Thy = thymus; WT = wild-type. Number of mice per probe $\geq 3$. 
nonoverlapping information. Therefore, although ${ }^{18} \mathrm{~F}-\mathrm{FLT}$ provides measurements of DNA-synthesizing activity and cell proliferation (30), dCK-specific probes may enable PETguided identification of cancer patients who are more likely to respond to cytotoxic chemotherapy nucleoside analog prodrugs. Furthermore, recently described mouse genetic models of TK1 (31) and dCK deficiency (5) provide invaluable tools to enable the identification of biologic processes that are critically dependent on the activity of these two cytosolic deoxyribonucleoside kinases.

\section{CONCLUSION}

We describe the development of a novel set of PET probes that can be used to measure the metabolic flux through the deoxyribonucleoside salvage pathway. A better understanding of the salvage pathway in terms of its physiologic function and potential role in cancer development and progression may expand the utility of TK1 and dCK-specific PET probes beyond their current status of surrogate markers for cell proliferation, immune activation, treatment stratification, and monitoring.

\section{ACKNOWLEDGMENTS}

We thank David Stout, Waldemar Ladno, and Judy Edwards for performing small-animal PET/CT; Rachel Laing for helping with experiments; and the cyclotron group for producing PET probes. This work was supported by the In Vivo Cellular and Molecular Imaging Centers Developmental Project Award NIH P50 CA86306; by R24CA92865, U.S. Department of Energy contract DE-FG02-06ER64249; by California Institute for Regenerative Medicine grant RT101126-1; and by funding from the Dana Foundation. Caius Radu, Owen Witte, and Johannes Czernin are among the inventors of the national and Patent Cooperation Treaty (PCT) patent applications for the FAC technology referred to in the article. That patent application was filed on September 19, 2008. A group of UCLA faculty members including Caius Radu, Johannes Czernin, Michael Phelps, and Owen Witte are involved in Sofie Biosciences, a startup company that has licensed this intellectual property.

\section{REFERENCES}

1. Staub M, Eriksson S. The role of deoxycytidine kinase in DNA synthesis and nucleoside analog synthesis. In: Peters GJ, ed. Cancer Drug Discovery and Development: Deoxynucleoside Analogs in Cancer Therapy. Totowa, NJ: Humana Press Inc.; 2006:29-52.

2. Eriksson S, Arner E, Spasokoukotskaja T, et al. Properties and levels of deoxynucleoside kinases in normal and tumor cells; implications for chemotherapy. Adv Enzyme Regul. 1994;34:13-25.

3. Durham JP, Ives DH. Deoxycytidine Kinase. I. Distribution in normal and neoplastic tissues and interrelationships of deoxycytidine and 1- $\beta$-D-arabinofuranosylcytosine phosphorylation. Mol Pharmacol. 1969;5:358-375.

4. Radu CG, Shu CJ, Nair-Gill E, et al. Molecular imaging of lymphoid organs and immune activation by positron emission tomography with a new $\left[{ }^{18} \mathrm{~F}\right]$-labeled 2'-deoxycytidine analog. Nat Med. 2008;14:783-788.

5. Toy G, Austin WR, Liao H-I, et al. Requirement for deoxycytidine kinase in T and B lymphocyte development. Proc Natl Acad Sci USA. 2010;107:5551-5556.
6. Ewald B, Sampath D, Plunkett W. Nucleoside analogs: molecular mechanisms signaling cell death. Oncogene. 2008;27:6522-6537.

7. Giovannoni G, Comi G, Cook S, et al. A placebo-controlled trial of oral cladribine for relapsing multiple sclerosis. N Engl J Med. 2010;362:416426.

8. Sabini E, Hazra S, Ort S, Konrad M, Lavie A. Structural basis for substrate promiscuity of dCK. J Mol Biol. 2008;378:607-621.

9. Lamba JK, Crews K, Pounds S, et al. Pharmacogenetics of deoxycytidine kinase: identification and characterization of novel genetic variants. J Pharmacol Exp Ther. 2007;323:935-945.

10. Galmarini CM, Mackey JR, Dumontet C. Nucleoside analogues: mechanisms of drug resistance and reversal strategies. Leukemia. 2001;15:875-890.

11. Radu CG, Witte ON, Nair-Gill ED, Satyamurthy N, Shu CJ, Czernin J, inventors; The Regents of the University of California, assignee. Positron emission tomography probes for imaging immune activation and selected cancers. US patent 2009/0105184. April 23, 2009.

12. Laing RE, Walter MA, Campbell DO, et al. Noninvasive prediction of tumor responses to gemcitabine using positron emission tomography. Proc Natl Acad Sci USA. 2009;106:2847-2852.

13. Ho DH. Distribution of kinase and deaminase of 1- $\beta$-D-arabinofuranosylcytosine in tissues of man and mouse. Cancer Res. 1973;33:2816-2820.

14. Richards DA, Sherwood RA, Ndebele D, Rocks BF. Determination of plasma cytidine deaminase activity by HPLC. Biomed Chromatogr. 1987;2: $148-151$.

15. Krenitsky TA, Tuttle JV, Koszalka GW, et al. Deoxycytidine kinase from calf thymus: substrate and inhibitor specificity. J Biol Chem. 1976;251:40554061.

16. Sun H, Collins JM, Mangner TJ, Muzik O, Shields AF. Imaging the pharmacokinetics of [F-18]FAU in patients with tumors: PET studies. Cancer Chemother Pharmacol. 2006;57:343-348.

17. Bonate PL, Arthaud L, Cantrell WR Jr, Stephenson K, Secrist JA, III, Weitman S. Discovery and development of clofarabine: a nucleoside analogue for treating cancer. Nat Rev Drug Discov. 2006;5:855-863.

18. Lotfi K, Mansson E, Spasokoukotskaja T, et al. Biochemical pharmacology and resistance to 2-chloro-2'-arabino-fluoro-2'-deoxyadenosine, a novel analogue of cladribine in human leukemic cells. Clin Cancer Res. 1999;5: 2438-2444.

19. Fanucchi MP, Watanabe KA, Fox JJ, Chou TC. Kinetics and substrate specificity of human and canine cytidine deaminase. Biochem Pharmacol. 1986;35: 1199-1201.

20. Maury G. The enantioselectivity of enzymes involved in current antiviral therapy using nucleoside analogues: a new strategy? Antivir Chem Chemother. 2000;11: $165-189$.

21. Sabini E, Hazra S, Konrad M, Lavie A. Nonenantioselectivity property of human deoxycytidine kinase explained by structures of the enzyme in complex with Land D-nucleosides. J Med Chem. 2007;50:3004-3014.

22. Kiianitsa K, Solinger JA, Heyer WD. NADH-coupled microplate photometric assay for kinetic studies of ATP-hydrolyzing enzymes with low and high specific activities. Anal Biochem. 2003;321:266-271.

23. Johansson M, van Rompay AR, Degreve B, Balzarini J, Karlsson A. Cloning and characterization of the multisubstrate deoxyribonucleoside kinase of Drosophila melanogaster. J Biol Chem. 1999;274:23814-23819.

24. Shewach DS, Liotta DC, Schinazi RF. Affinity of the antiviral enantiomers of oxathiolane cytosine nucleosides for human 2 '-deoxycytidine kinase. Biochem Pharmacol. 1993;45:1540-1543.

25. Shields AF, Grierson JR, Muzik O, et al. Kinetics of $3^{\prime}$-deoxy-3'-[F-18] fluorothymidine uptake and retention in dogs. Mol Imaging Biol. 2002;4:83-89.

26. Shields AF, Grierson JR, Dohmen BM, et al. Imaging proliferation in vivo with [F-18]FLT and positron emission tomography. Nat Med. 1998;4:1334-1336.

27. Morse HC, 3rd, Davidson WF, Yetter RA, Murphy ED, Roths JB, Coffman RL. Abnormalities induced by the mutant gene lpr: expansion of a unique lymphocyte subset. J Immunol. 1982;129:2612-2615.

28. Kelley VE, Roths JB. Interaction of mutant lpr gene with background strain influences renal disease. Clin Immunol Immunopathol. 1985;37:220-229.

29. van Waarde A, Cobben DC, Suurmeijer AJ, et al. Selectivity of ${ }^{18} \mathrm{~F}-\mathrm{FLT}$ and ${ }^{18} \mathrm{~F}-$ FDG for differentiating tumor from inflammation in a rodent model. $\mathrm{J}$ Nucl Med. 2004;45:695-700.

30. Bading JR, Shields AF. Imaging of cell proliferation: status and prospects. J Nucl Med. 2008;49(suppl 2):64S-80S.

31. Dobrovolsky VN, Bucci T, Heflich RH, Desjardins J, Richardson FC. Mice deficient for cytosolic thymidine kinase gene develop fatal kidney disease. $\mathrm{Mol}$ Genet Metab. 2003;78:1-10. 